ARTICLE

\title{
Analysis of Drone Fleet Type and Quantity for Medical Package Dis- tribution in Emergency System
}

\section{Yujie Jiang ${ }^{1}$ Shizhong $\mathrm{Ma}^{2^{*}}$ Shilong $\mathrm{Zhu}^{3}$}

1. School of Economics, North China University of Science and Technology, Tangshan, Hebei, 063210, China

2. College of Electrical Engineering, North China University of Science and Technology, Tangshan, Hebei, 063210, China

3. College of Science, North China University of Science and Technology, Tangshan, Hebei, 063210, China

\begin{tabular}{ll}
\hline ARTICLE INFO & ABSTRACT \\
\cline { 2 - 2 } $\begin{array}{l}\text { Article history } \\
\text { Received: } 17 \text { January } 2020\end{array}$ & $\begin{array}{l}\text { In order to cope with the disasters caused by the worst hurricane in } \\
\text { Puerto Rico in 2017, it is necessary to build an emergency system to } \\
\text { Revised: 24 January } 2020\end{array}$ \\
reduce the losses. An emergency system should include the location of \\
ISO standard dry cargo containers and the distribution of emergency \\
medical packages. This paper discusses the distribution of emergency \\
medical package. Based on the above location results of ISO standard \\
dry cargo container, taking the demand of disaster areas not exceed \\
its supply into consideration and considering the timeliness and weak \\
economy, a multi-objective mixed integer programming model is con- \\
Keywords:
\end{tabular}$\quad \begin{aligned} & \text { structed on the premise of minimum transportation time and cost. It } \\
& \text { is determined that the drone fleet consists of four B, one C and one F } \\
& \text { drones. Through the optimization model, the distribution plan of emer- } \\
& \text { Multi-objective mixed integer programming } \\
& \text { gency medical packages is formulated. }\end{aligned}$

\section{Emergency Medical Package Allocation}

\section{Model}

$\mathrm{I}$ a disaster area is supported by multiple reserve points, it is assumed that multiple reserve points support the disaster area on average. The demand of the disaster area is distributed to the reserve point on average, and the formula is as follows: $a_{i j}=\frac{1}{n} b_{j}$, Among them, $a_{i j}$ represents the demand of the $j$ th disaster area support- ed by the $i$ th reserve point and $b_{j}$ represents the total demand of the $j$ th disaster area. The formula for calculating the demand of reserve point is $P_{i}=\sum_{j=1}^{n} a_{i j}$, where $\mathrm{p}$ is the demand of the $i$ th reserve point.

In order to simplify the model, considering that the distribution of emergency medical packages is a dynamic process, hypothetical conditions are proposed.

(1) Transportation time and cost are calculated accurately. There are no accidents on the way, and the cost is only related to the length of transportation.

*Corresponding Author:

Shizhong Ma,

Corresponding address:East District of North China University of Technology No. 21 Bohai Avenue, Tangshan Bay Ecological City, Caofeidian District, Tangshan City, Hebei Province, China;

E-mail:1643360071@qq.com 
(2) The demand of the reserve point can be supplied in the first time without additional production and supply.

According to the above analysis and given parameters, in the process of emergency rescue, due to the timeliness and weak economy, the time and cost of rescue are minimized within the prescribed rescue time. According to the above analysis, the constraints of the model are summarized as follows:

(1) The total number of emergency medical packages dispatched from each reserve point does not exceed its reserve;

(2) The total number of emergency medical packages accepted by a reserve point is equal to its demand.

(3) The time of dispatching emergency medical packages to each reserve point does not exceed the prescribed rescue time.

Based on the above assumptions and analysis, the following models are established:

$$
\begin{aligned}
& \min T=\max \left\{x_{i j} T_{i j}\right\} \\
& \min G=\sum_{i=1}^{m} \sum_{j=1}^{n} x_{i j} C_{i j} \\
& \text { s.t. }\left\{\begin{array}{l}
\sum_{j=1}^{n} x_{i j} G_{i j} \leq G_{i} \\
\sum_{i=1}^{m} x_{i j} G_{i j}=D_{j} \\
\sum_{j=1}^{n} D_{j} \leq \sum_{i=1}^{m} G_{i} \\
T \leq T_{0} \\
x_{i j}=\{0,1\}
\end{array}\right.
\end{aligned}
$$

Among them, $m$ refers to the number of reserve points marked as $A_{1}, A_{2}, \ldots, A_{m} ; x_{i j}$ : when emergency medical packages are delivered from reserve point $A_{i}$ to reserve sites $B_{i}, x_{i j}=1$, otherwise $x_{i j}=0$.

\section{The Solution of Drone Fleet and Emergen- cy Medical Packages Distribution Model}

Firstly, the flight speed and duration of drone are taken as the index to evaluate its performance. The performance of drone is ranked as B, F, C, G, D, E, A and H. Due to the limited load capacity and warehouse capacity of drone, we can get how many medical packages each drone can carry:
Table 1. Quantitative analysis table of medical package carrying capacity of drone

\begin{tabular}{|c|c|c|c|c|c|c|c|c|}
\hline Drones' type & A & B & C & D & E & F & G & H \\
\hline MED1 & 1 & 2 & 4 & 1 & 2 & 2 & 2 & N \\
\hline MED2 & 1 & 2 & 5 & 1 & 3 & 3 & 3 & N \\
\hline MED3 & 1 & 2 & 3 & 1 & 2 & 2 & 2 & N \\
\hline
\end{tabular}

Then the problem of emergency medical package allocation is solved. When solving the problem of medical package allocation, it is assumed that the transportation cost is only proportional to the distance between routes. Therefore, the model is simplified to :

$$
f_{\text {min }}=\sum_{i=1}^{m} \sum_{j=1}^{n} x_{i j} T_{i j}
$$

$$
\text { s.t. }\left\{\begin{array}{l}
\sum_{j=1}^{n} x_{i j} G_{i j} \leq G_{i} \\
\sum_{i=1}^{m} x_{i j} G_{i j}=D_{j} \\
\sum_{j=1}^{n} D_{j} \leq \sum_{i=1}^{m} G_{i} \\
x_{i j}=\{0,1\}
\end{array}\right.
$$

Through calculation, the number of emergency medical packages transported to hospitals is as follows. The daily needs of hospitals in disaster areas for various types of medical packages are 7 MED1 medical packages, 2 MED2 medical packages and 4 MED1 medical packages. By analyzing the relative distance and the carrying capacity of drone, the optimal drone fleet composition (Table 3) and ISO cargo container packaging configuration (Table 4) are obtained.

Table 2. Optimal fleet composition table for drones

\begin{tabular}{|rl|c|c|}
\hline $\begin{array}{r}\text { Types and quantities } \\
\text { of medical packages }\end{array}$ & $\begin{array}{r}\text { Types and Quantities of } \\
\text { Unmanned Aerial Vehicles }\end{array}$ & $\begin{array}{c}\text { Composition of } \\
\text { drone fleet }\end{array}$ \\
\cline { 1 - 2 } MED1 & 7 & $\begin{array}{r}\text { Two B-type and C-type are } \\
\text { required respectively. }\end{array}$ & \multirow{2}{*}{$\begin{array}{c}\text { 4 B-types } \\
\text { 1 C-types }\end{array}$} \\
\cline { 1 - 2 } MED2 & 2 & Require a B-Type drone & \multirow{2}{\text{1F-typedrone}}{} \\
\cline { 1 - 2 } MED1 & 4 & $\begin{array}{r}\text { Need 1 B-type } \\
\text { And F-type drone }\end{array}$ & \\
\hline
\end{tabular}

Table 3. ISO Container Packaging Configuration Table

\begin{tabular}{|c|c|c|c|}
\hline & ISO1 & ISO2 & ISO3 \\
\hline MED1 & 6 & 6 & 6 \\
\hline MED2 & 1 & 1 & 1 \\
\hline MED3 & 6 & 6 & 6 \\
\hline
\end{tabular}


The drone flight plan:According to the analysis and solution of $\mathrm{A}$ and $\mathrm{B}$, we make the delivery route of drones as shown in Figure 1.

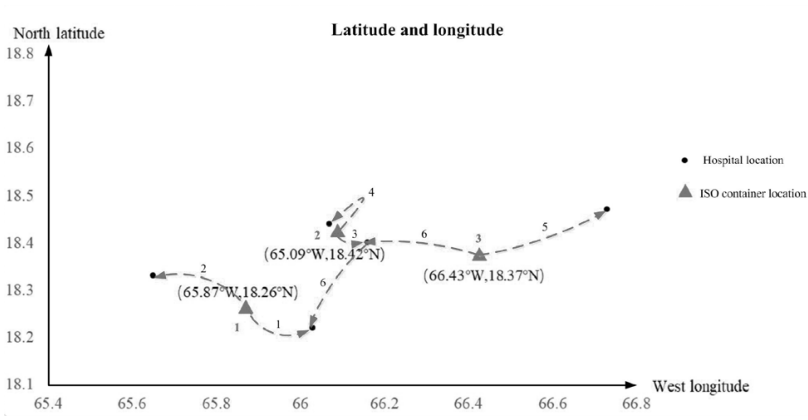

Figure 1. Medical packages delivery route of drones

Generally, there is only one route to the designated medical sites, that is, Route 1 is from container 1 to Caribbean Medical Center, Route 2 is from container 1 to Hospital HIMA, route 3 is from container 2 to Hospital Pavia Santurce, Route 4 is from container 2 to Puerto Rico Children's Hospital, Route 5 is from container 3 to Hospital Pavia Arecibo.

Considering the occurrence of accidents, we set up two more routes, which is from container 3 to Hospital HIMA and Peuerto Rico Children's Hospital. Usually, these two routes are used by drones to detect roads separately, but they can be temporarily used as transportation routes when necessary.

After the analysis and solution of problems A and B, in order to ensure that medical packages can be delivered first every day and the specific road conditions can be known within one day, the following drone delivery schedule is roughly made:

Table 4. The delivery schedule of drone fleet

\begin{tabular}{|c|c|c|c|}
\hline route & drone type & delivery time & return time \\
\hline 1 & $\mathrm{~B}_{1}$ & $6: 00 \mathrm{am}-6: 30 \mathrm{am}$ & 7:00am-7:17am \\
\hline 2 & $\mathrm{~B}_{2}$ & $6: 00 \mathrm{am}-6: 30 \mathrm{am}$ & 7:00am-7:17am \\
\hline 3 & $\mathrm{~B}_{3}$ & $6: 00 \mathrm{am}-6: 10 \mathrm{am}$ & $6: 30 \mathrm{am}-6: 35 \mathrm{am}$ \\
\hline 4 & $\mathrm{~B}_{3}+\mathrm{F}$ & $7: 00 \mathrm{am}-7: 10 \mathrm{am}$ & $7: 30 \mathrm{am}-7: 35 \mathrm{am}$ \\
\hline 5 & $\mathrm{C}$ & $6: 00 \mathrm{am}-6: 35 \mathrm{am}$ & 7:00am-7:27am \\
\hline $\begin{array}{c}\text { 6(highway inves- } \\
\text { tigation) }\end{array}$ & $\mathrm{B}_{4}$ & $6: 00 \mathrm{am}--$ & \\
$1 / 14: 00 \mathrm{pm}--$ & \\
$120: 00 \mathrm{pm}--$ & \\
\hline
\end{tabular}

Where, drone $\mathrm{B}_{1}$, drone $\mathrm{B}_{2}$, drone $\mathrm{B}_{3}$, and drone $\mathrm{F}$ are delivery drones and drone $\mathrm{B}_{4}$ are reconnaissance drones.

Through the above analysis, our team's packing ar- rangements for drones are as follows:

Table 5. Packaging arrangement of drone

\begin{tabular}{|c|c|c|c|c|c|c|}
\hline & $\mathrm{B}_{1}$ & $\mathrm{~B}_{2}$ & $\mathrm{~B}_{3}$ & $\mathrm{~F}$ & $\mathrm{C}$ & $\mathrm{B}_{4}$ \\
\hline MED1 & 1 & 2 & 1 & 1 & 1 & 0 \\
\hline MED2 & 0 & 0 & 1 & 0 & 0 & 0 \\
\hline MED3 & 1 & 1 & 0 & 2 & 0 & 0 \\
\hline
\end{tabular}

Delivery drones transport medical packages from reserve sites to the demand sites through strict routes. At the same time, each group of drones transport video configuration, can carry out video recording in the process of cargo transport, provide the company with video basis, combined with independent survey of drone video, so that the company knows the damage or usability of roads, and then on land. Route planning to achieve land rescue.

Starting from the last container, the reconnaissance drones reconnoitre the roads near five demand sites and videotape them to provide timely feedback on road information-damage or usability, so as to facilitate HELP, Inc. to understand the road damage situation, and to provide land rescue to the affected areas, plan rescue time, dispatch rescue personnel and send support equipment. The other drones of types B, except for the first delivery time, reconnoitre the roads around the hospital in the same time as $\mathrm{B}_{4}$, and report the damage or usability of the roads in time. Since the disaster is sustained, we plan to conduct road reconnaissance three times one day to avoid sudden road damage, which prevent land support from reaching in time.

The specific flight plan is shown in the following figure.

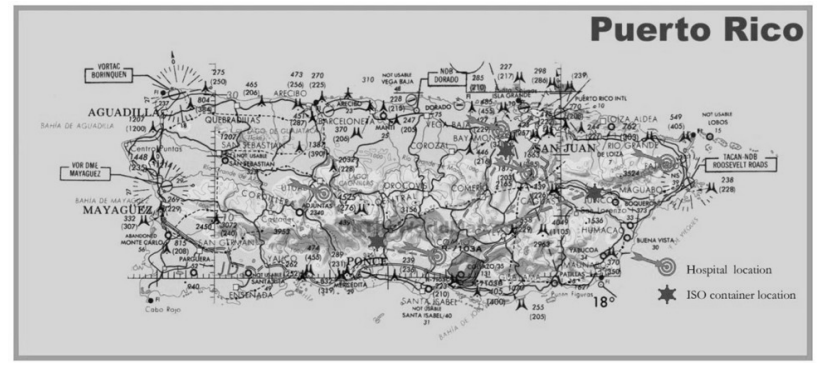

Figure 2. The flight road map of drone Fleet

\section{Reference}

[1] Khan J U, Qureshi B A, Zubair S M. A comprehensive design and performance evaluation study of counter flow wet cooling towers[J]. International Journal of Refrigeration, 2004, 27(8): 914-923.

[2] Espadas J, Molina A, Guillermo Jiménez, et al. A 
tenant-based resource allocation model for scaling Software-as-a-Service applications over Cloud computing infrastructures[J]. Future Generation Computer Systems, 2013, 29(1).

[3] Ben-Elia E, Shiftan Y. Which road do I take? A learning-based model of route-choice behavior with real-time information[J]. Transportation Research Part A: Policy and Practice, 2010, 44(4): 0-264.
[4] Shim D H, Chung H, Kim H J, et al. Autonomous Exploration In Unknown Urban Environments For Unmanned Aerial Vehicles[J]. IEEE Robotics \& Automation Magazine, 2005, 13(3).

[5] Henriet F, Stéphane Hallegatte, Tabourier L. Firm-network characteristics and economic robustness to?natural disasters[J]. Journal of Economic Dynamics and Control, 2012, 36(1): 150-167. 